\title{
A study on the surface and crack tip oxidation of Alloy 600 through high- resolution characterization
}

\author{
Kai Chen ${ }^{\mathrm{a}}$, Zhao Shen ${ }^{\mathrm{b}}$ * \\ ${ }^{a}$ School of Nuclear Science and Engineering, Shanghai Jiao Tong University, 800 Dongchuan Road, Shanghai \\ 200240, China \\ ${ }^{\mathrm{b}}$ Department of Materials, University of Oxford, Parks Road, OX1 3PH Oxford, UK \\ Corresponding author: zhao.shen@materials.ox.ac.uk
}

\begin{abstract}
Surface, stagnant grain boundary (GB), and crack tip oxidation of Alloy 600 were studied. The mirror-finished surface oxide has a duplex structure and the formation mechanisms of each layer are discussed. A more compact oxide film is observed on the cold-worked surface, while the nano-GBs are preferentially oxidized. The crack tip oxidation rate is around four orders of magnitude faster than that of the stagnant GB, and their oxidation mechanisms are believed to be the same. Diffusion-induced grain boundary migration (DIGM) is observed around the crack and oxidized GB tips. The role of Ni expulsion on the DIGM is discussed.
\end{abstract}

Key words: Alloy 600; Internal oxidation; Surface finish; Cold work; Stress corrosion cracking.

\section{Introduction}

Intergranular stress corrosion cracking (IGSCC) of Ni-based Alloy 600 in the primary water of pressurized water reactor (PWR) has been a challenging issue faced by the nuclear power industry since the first failure reported by Coriou et al. in 1959 [1]. Thereafter, despite the fact that a large number of laboratory studies have been performed and several possible models proposed to explain the IGSCC phenomenon [2-6], the exact failure mechanisms driving IGSCC propagation remain unclear. To date, plenty of parameters have been reported to have influence on SCC, including temperature, alloy composition, cold-work, electrochemical potential, and stress [6-22]. The problem is further convoluted as the parameters listed above are not independent. Although it seems that a single model cannot explain the entire spectrum of IGSCC failure, currently there is growing evidence to support an intergranular selective oxidation model $[2,8-15,19,20,23]$, in which oxygen diffusing into the grain boundary (GB) ahead of crack tips and leading to intergranular selective oxidation.

Scott et al. [2] initially proposed the intergranular selective oxidation model after analyzing a series of thermodynamic and kinetic features associated with cracking in Alloy 600. This model was proposed based on two basic observations: that the oxidation of Alloy 600 exposed to the PWR primary water is mainly along GBs and that the cracking is intergranular. In addition, the authors believed that the oxide growing along the GBs is more brittle than the metal matrix, and therefore leads to the embrittlement of the GBs. This embrittled GB could then act as a preferable cracking pathway in the material, resulting in intergranular cracking under external stress. According to the model proposed by Scott et al. [2], the fracture occurs in stages, with oxygen penetrating down a section of GB, leading to oxide growth and embrittlement, before a crack propagates into that particular section. Once the oxidized section is opened up, oxygen can diffuse further into the GB, oxidizing a deeper region of the GB, which then also cracks under applied external stress.

The surface oxidation of Ni-based alloys after exposure to the PWR primary water is another challenge to the nuclear power industry due to the release of ${ }^{58} \mathrm{Ni}$ cations into the primary water. The released ${ }^{58} \mathrm{Ni}$ cations will be activated into ${ }^{58} \mathrm{Co}$ cations in the nuclear core under neutron flux, resulting in the increase of global radioactivity of the primary circuit [24]. To protect the staff during maintenance, the release of ${ }^{58} \mathrm{Ni}$ cations has to be well controlled. According to the work in the literature [24-32], an oxide film will form during the surface oxidation, which is believed to play a key role in protecting the materials from further oxidation and cation release. To date, the oxide film formed on the Ni-based alloys after exposure to high temperature water has been intensively studied in order to obtain a better understanding of the mechanisms governing the phenomena of oxidation and cation release [24-32]. The oxide film formed on the Ni-based alloys is generally reported to have a double-layered structure consisting of an inner oxide layer (IOL) and an outer oxide layer (OOL) [24-32]. The OOL is mainly composed of discrete $\mathrm{Fe} / \mathrm{Ni}$-rich oxide particles, whereas the IOL is protective and enriched in Cr [24-32]. 
Recent work reports that the IGSCC properties are significantly affected by the oxidation occurred in the region ahead of the IGSCC crack tip [2, 8-15, 19, 20,23]. The oxide formed in front of crack tip is referred to as crack tip oxide in the current study. Due to the small volume inside the IGSCC cracks, the water chemistry around the IGSCC crack tips is believed to be different from that outside the IGSCC cracks $[33,34]$. As a result, the oxidation mechanism controlling the crack tip oxidation is supposed to be different from the surface oxidation mechanism $[33,34]$. However, to date, there is still no solid evidence to show the correlation between the surface and crack tip oxidation, although they have been extensively studied in the literature [2, 8-15, 19, 20, 23-32]. As a result, a comparative study between the oxides developed on the surface and at the IGSCC crack tip is required.

It is generally believed that the structural components used in the PWR primary circuit will inevitably suffer cold-work during manufacturing and installation. In addition, recently, localized deformation zone (LDZ) was experimentally observed around the IGSCC crack tips by Meisnar et al. [9] and Shen et al. [14] through transmission Kikuchi diffraction (TKD). The authors reported that the external loading-induced LDZ could enhance oxidation through accelerating the elemental diffusion. Similar results were also reported in studies of surface oxidation and suggested that the dislocations induced by cold-work could have significant effect on surface oxidation behaviors [27, 35-40]. To understand the effect of dislocations on oxidation, a comparative study between the oxides formed on surface with different extend of deformation may shed light on it.

In the current study, a 20\% cold-worked Alloy 600 is used for surface oxidation and IGSCC tests. After the tests, in-situ focused ion beam (FIB) sample preparation techniques were used to prepare thin foils containing IGSCC crack tips or surface oxide. The oxides formed on the surface and in front of IGSCC crack tips were analysed and compared by high-resolution characterization. With the results reported in this study, a better understanding of the relationship between the surface and crack tip oxidation has been obtained.

\section{Experimental}

\subsection{Material and experiments}

The material used in this study is a $20 \%$ cold-worked Alloy 600. Cold-work in the material was conducted through uni-directional rolling at room temperature. Prior to autoclave testing and cold rolling, the specimens were mill-annealed in air at $930{ }^{\circ} \mathrm{C}$ followed by water quenching. Due to the relatively high $\mathrm{C}$ content in this material, the heat treatment used for this material introduced carbide precipitation at the GBs, resulting in intergranular $\mathrm{Cr}$ depletion. The intergranular carbide coverage was measured to be around $30 \%$. More details about the microstructure of the intergranular carbides can be found in [29]. Table 1 shows the chemical composition of this material. The chemical composition was provided by Institute of Nuclear Safety Systems (Japan) and further confirmed by atom probe tomography analysis. The microstructure of this material was examined via electron backscattered diffraction (EBSD). Fig. 1a shows the GB distribution in the metal matrix, and the average grain size is measured to be $\sim 120 \mu \mathrm{m}$ (see Fig. 1b). Fig. 1c shows the kernel misorientation (KMO) map, revealing the non-uniform deformation with higher KMO values near GBs. More details about this material can be found in [41].

Table 1 Chemical composition of the alloy used in this study (wt\%).

\begin{tabular}{cccccccccc}
\hline Material & $\mathrm{C}$ & $\mathrm{Cr}$ & $\mathrm{Fe}$ & $\mathrm{Si}$ & $\mathrm{Mn}$ & $\mathrm{P}$ & $\mathrm{S}$ & $\mathrm{Cu}$ & $\mathrm{Ni}$ \\
\hline Alloy 600 & 0.06 & 16.02 & 6.94 & 0.33 & 0.35 & 0.006 & $<0.001$ & 0.03 & 76.26 \\
\hline
\end{tabular}




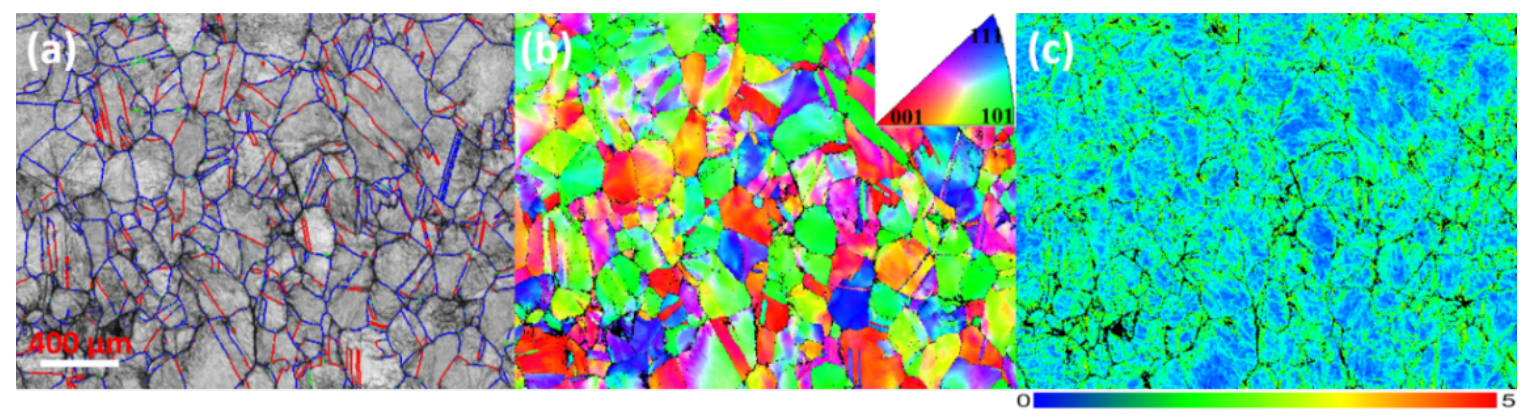

Fig. 1. Microstructure of Alloy 600 obtained from EBSD (step size $=4 \mu \mathrm{m}$ ) analysis. (a) Distribution of GBs ( $\sum 3$ in red, high angle GB in blue); (b) inverse pole figure (z-axis) (IPFZ) map; (c) KMO map.

The IGSCC test was conducted on a pre-cracked 0.5T compact tension (CT) specimen in simulated PWR primary water $(500 \mathrm{ppm} \mathrm{B}+2 \mathrm{ppm} \mathrm{Li})$ under a constant stress intensity factor $(\mathrm{K})$ of $30 \mathrm{MPa} \mathrm{m}{ }^{1 / 2}$ at $340^{\circ} \mathrm{C}$. The dissolved hydrogen was continuously bubbled into the inlet water, and created a corrosion potential located around the equilibrium of $\mathrm{Ni} / \mathrm{NiO}$ [22]. The measured crack growth rate (CGR) was $1.6 \times 10^{-6} \mathrm{~mm} / \mathrm{s}$. After the test, the cross-section of the CT specimen was mechanically polished until obtaining a mirror-finished surface, as shown in Fig. 2. Four potentially active crack tips are pointed out in Fig. 2, which were used for the IGSCC crack tip characterizations.

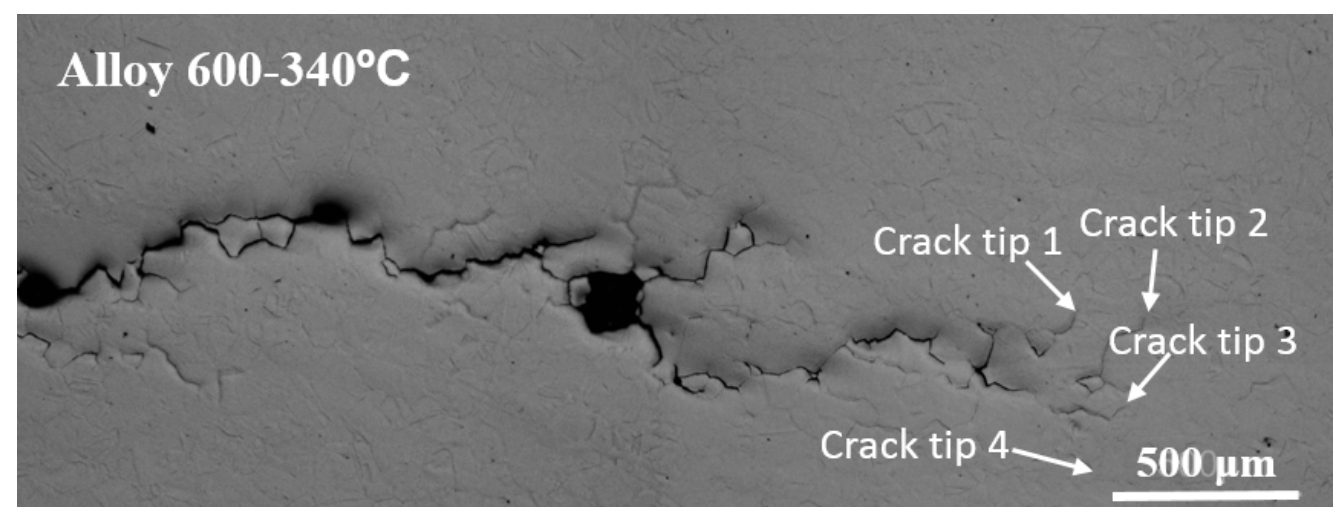

Fig. 2. Optical micrograph of the cross-sectional surface of the CT specimen after IGSCC testing at $340^{\circ} \mathrm{C}$ in simulated PWR primary water.

Two 20\% cold-worked Alloy 600 coupons were prepared for the study of surface oxidation. One was mechanically ground using $\mathrm{SiC}$ papers up to 2000 grit, followed by colloidal silica polishing to obtain a mirrorfinished surface. The other coupon was mechanically ground using $\mathrm{SiC}$ papers up to 1000 grit (refer to as a cold-worked surface). The two coupons were exposed in the autoclave at $340^{\circ} \mathrm{C}$ for $2000 \mathrm{~h}$ with the same water chemistry as used in the IGSCC test.

\subsection{Methodology}

\subsubsection{FIB site-specific sample preparation}

To study the oxides formed on surface and ahead of the crack tip, FIB cross-section and plan-view sample preparation techniques were developed and utilized to prepare thin transmission electron microscopy (TEM) foils. A single beam FEI FIB200 equipped with a static micromanipulator was used for trenching and in-situ lift-out. A dual beam Zeiss NVision 40 FIB-SEM was subsequently used for thinning sample to a thickness less than $50 \mathrm{~nm}$. Finally, low energy cleaning $(5 \mathrm{kV}, 250 \mathrm{pA})$ with FIB was performed on both sides of the thin foils to minimize the damage introduced by FIB milling.

\subsubsection{TEM analysis}

A JEOL 2100 (operating voltage $200 \mathrm{kV}$ ) was used for TEM imaging and selected area electron diffraction (SAED). High angle annular dark field (HAADF) imaging and electron energy loss spectroscopy (EELS) were 
conducted with a JEOL ARM200F operating at $200 \mathrm{kV}$ and equipped with a Quantum Gatan image filter (GIF) spectrometer. EELS quantification was performed in Digital Micrograph by the background subtraction method. The relatively low thickness of the TEM foils used in this study $(\sim 50 \mathrm{~nm})$ allowed for a reliable quantification without removing plural scattering. This was checked for regions of known composition (e.g. the matrix).

\subsubsection{TKD analysis}

On the site-specific TEM samples, TKD analysis was performed using a Zeiss Merlin FEG-SEM equipped with the Optimus TKD Detector that allows for better spatial resolution with minimal sample drift. The sample was held normal to the electron beam at a working distance of $5 \mathrm{~mm}$ and Kikuchi patterns captured underneath with a horizontal phosphor screen at an accelerating voltage of $20 \mathrm{kV}$ and a probe current of $1.5 \mathrm{nA}$. The step size was set to $10 \mathrm{~nm}$. The data was subsequently post-processed by Channel 5 software to obtain image quality, misorientation (MO), and inverse pole figure (z-axis) (IPFZ) maps.

\section{Results}

\subsection{Oxidation on the mirror-finished surface}

\subsubsection{Intragranular oxidation}

Fig. 3 shows the morphologies of the surface oxide formed on the Alloy 600 coupon with a mirror-finished surface after exposure to simulated PWR primary water at $340^{\circ} \mathrm{C}$ for $2000 \mathrm{~h}$. The oxide particles are observed on the outer surface. The growth direction of these oxide particles appears to be along a specific orientation within one grain and varies from matrix grain to grain, as shown in Figs. 3a and b. The size of the oxide particles is not uniform, ranging from $500 \mathrm{~nm}$ to $5 \mu \mathrm{m}$ (see Fig. 3c). At increased magnification, a layer of finer oxide particles is observed. The size of these fine crystallites is smaller than $10 \mathrm{~nm}$ (see Fig. 3d).

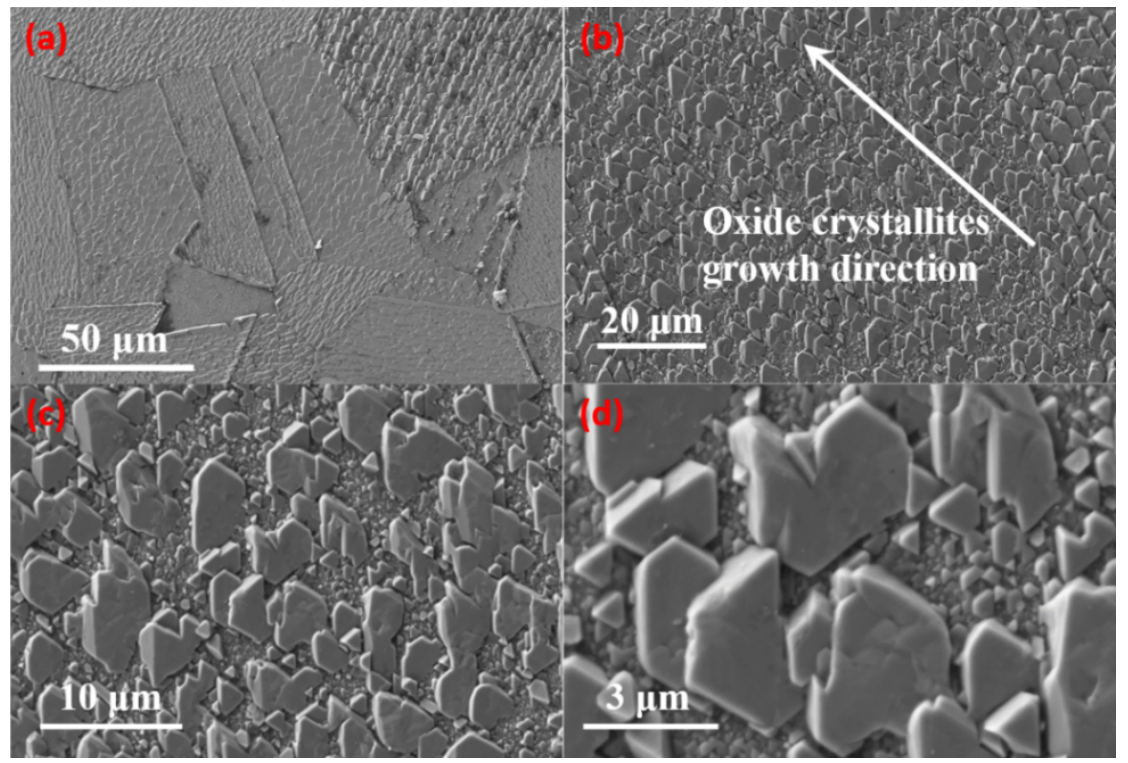

Fig. 3. Morphology of the surface oxide formed on Alloy 600 with a mirror-finished surface after exposure to simulated PWR primary water at $340^{\circ} \mathrm{C}$ for $2000 \mathrm{~h}$.

The cross-section of the oxide film on the mirror-finished coupon was examined by HAADF imaging. Six different regions were analyzed and one of the representative results is shown in Fig. 4. Due to the different atomic density between the matrix and the oxide, it is easy to differentiate these two phases in the HAADF image. Further observation reveals that the signal intensity in the surface oxide film is not uniform. The surface oxide film can be divided into two layers, an IOL and an OOL, based on their different signal intensity. The original sample surface seems to be located at the IOL-OOL interface since this interface is flat, which is coincide with the mirror-finished surface. The thickness of the IOL is $\sim 100 \mathrm{~nm}$. In addition, many white particles were observed to distribute discretely within the IOL. 
Fig. 4b shows the EELS signal intensity maps of the element distributions, in which a brighter contrast indicates a greater net signal count. In the O-map, the signal intensity in the IOL is higher than OOL. In addition, the O signal intensity in the white particles (see Fig. 4a) is much lower than in the surrounding oxide. There is nearly no oxygen in the large white particles (marked by the red dashed circle in Fig. 4a). The Cr-map reveals that $\mathrm{Cr}$ is depleted in the OOL, while enriched in the IOL. The distribution of $\mathrm{Cr}$ in the IOL is not uniform and is depleted within the white particles. The Fe-map shows that Fe is not only enriched in the OOL but also in the $\mathrm{IOL}$, and $\mathrm{Fe}$ is also depleted in the white particles. The Ni-map shows that the white particles in the IOL are enriched in $\mathrm{Ni}$ (nearly exhausted in $\mathrm{O}, \mathrm{Fe}$ and $\mathrm{Cr}$ ). In addition to the obvious duplex oxide layers, a narrow $\mathrm{Fe} / \mathrm{Cr}$-depleted and Ni-enriched layer is observed at the IOL-matrix interface, with the thickness of $\sim 30 \mathrm{~nm}$. It is necessary to point out that the measured thickness of this layer may have been exaggerated due to the TEM projection overlap. Since the chemical composition in this layer is different from the metal matrix, it is referred to as a Ni-rich layer as marked by the red dashed lines. Although oxygen is also observed in this layer, it is supposed to be due to the overlap between the metallic Ni-rich layer and the IOL since the signal intensity of oxygen in the Ni-rich layer is much lower than in the IOL. An EELS line-scan was conducted to quantify the chemical composition across the surface oxide film. The position of the EELS line-scan is marked in the Crmap (see Fig. 4b). The interfaces of different layers can be distinguished according to their different chemical compositions. As shown in Fig. 4c, I, II, and III represent the OOL, IOL, and Ni-rich layer, respectively. There is a sharp oxygen gradient in the Ni-rich layer, which further proves that the oxygen in the Ni-rich layer is due to overlapping.
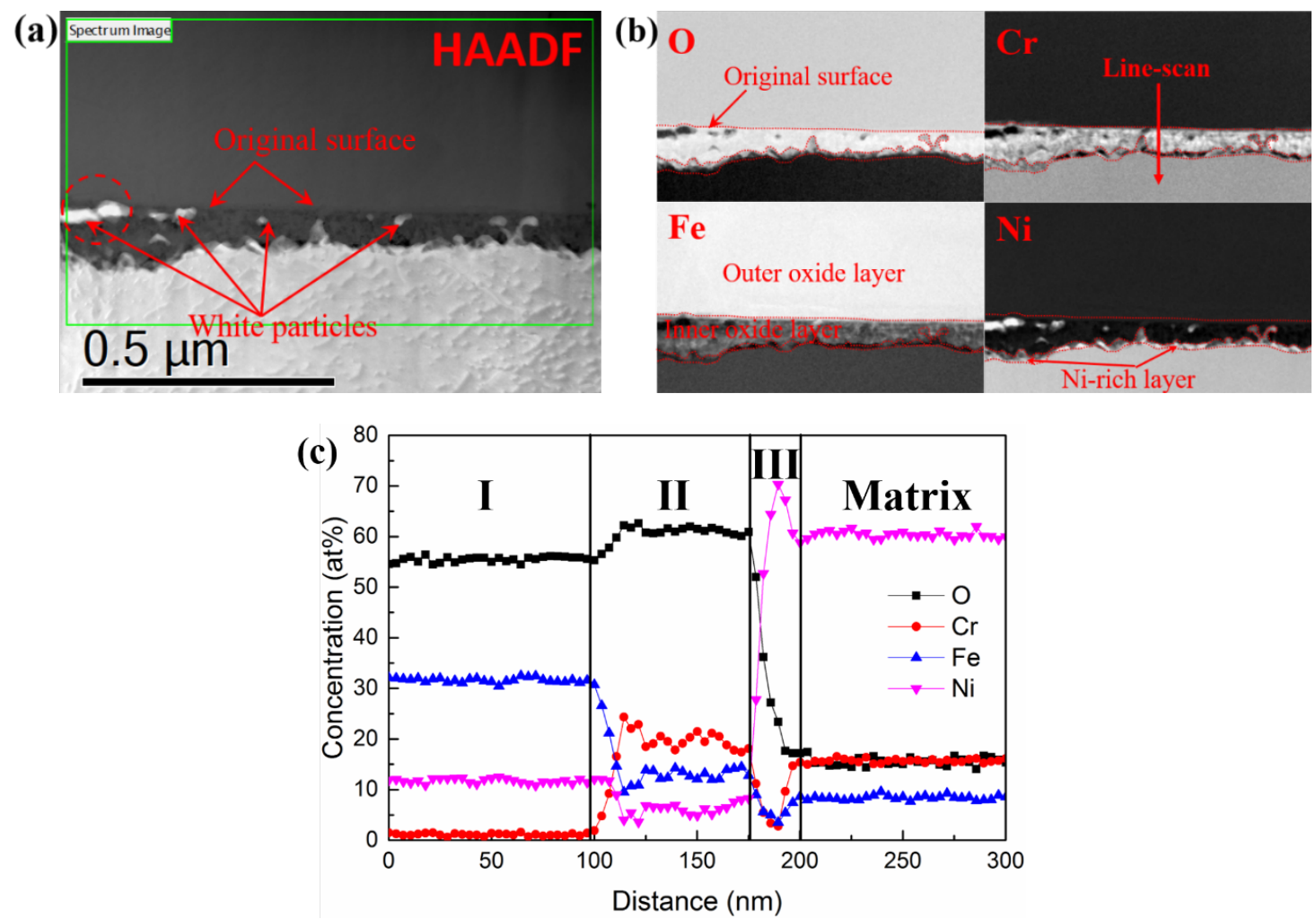

Fig. 4. The cross-section of the surface oxide formed on Alloy 600 with a mirror-finished surface. (a) HAADF image; (b) EELS elemental $\mathrm{O} \mathrm{K}$ edge and $\mathrm{Cr} / \mathrm{Fe} / \mathrm{Ni}$ L edge maps (signal intensity); (c) EELS composition line profiles across the surface oxide.

Fresnel contrast TEM imaging was conducted on the cross-section of the oxide film. Six different regions were analyzed, and one of the representative results is shown in Fig. 5. A duplex oxide structure of the surface oxide film is confirmed according to the image contrast (see Fig. 5a). In addition, the Ni-rich layer is also observed at the IOL-matrix interface. The OOL appears to be compact and no cavities are observed. The IOL is not compact since nano-cavities are observed at the interface between the IOL and Ni-rich layer as pointed out in Fig. 5c. Fig. $5 \mathrm{~d}$ shows the SAED pattern obtained from the matrix, revealing an austenite phase. The SAED pattern in 
Fig. $5 \mathrm{f}$ shows that the OOL has a spinel structure. Together with the EELS results (see Fig. 4c), the outer layer particles can be characterized as $(\mathrm{Ni}, \mathrm{Fe})_{3} \mathrm{O}_{4}$. The SAED pattern in Fig. 5e shows that the IOL consisted of multi-crystallites. These crystallites are identified as a mixture of $\mathrm{Cr}-\mathrm{Fe}-\mathrm{Ni}$ spinel and $\mathrm{Cr}_{2} \mathrm{O}_{3}$. Further observation reveals a crystallographic epitaxial relationship between the matrix and the surface oxides (inner oxide and outer oxide).
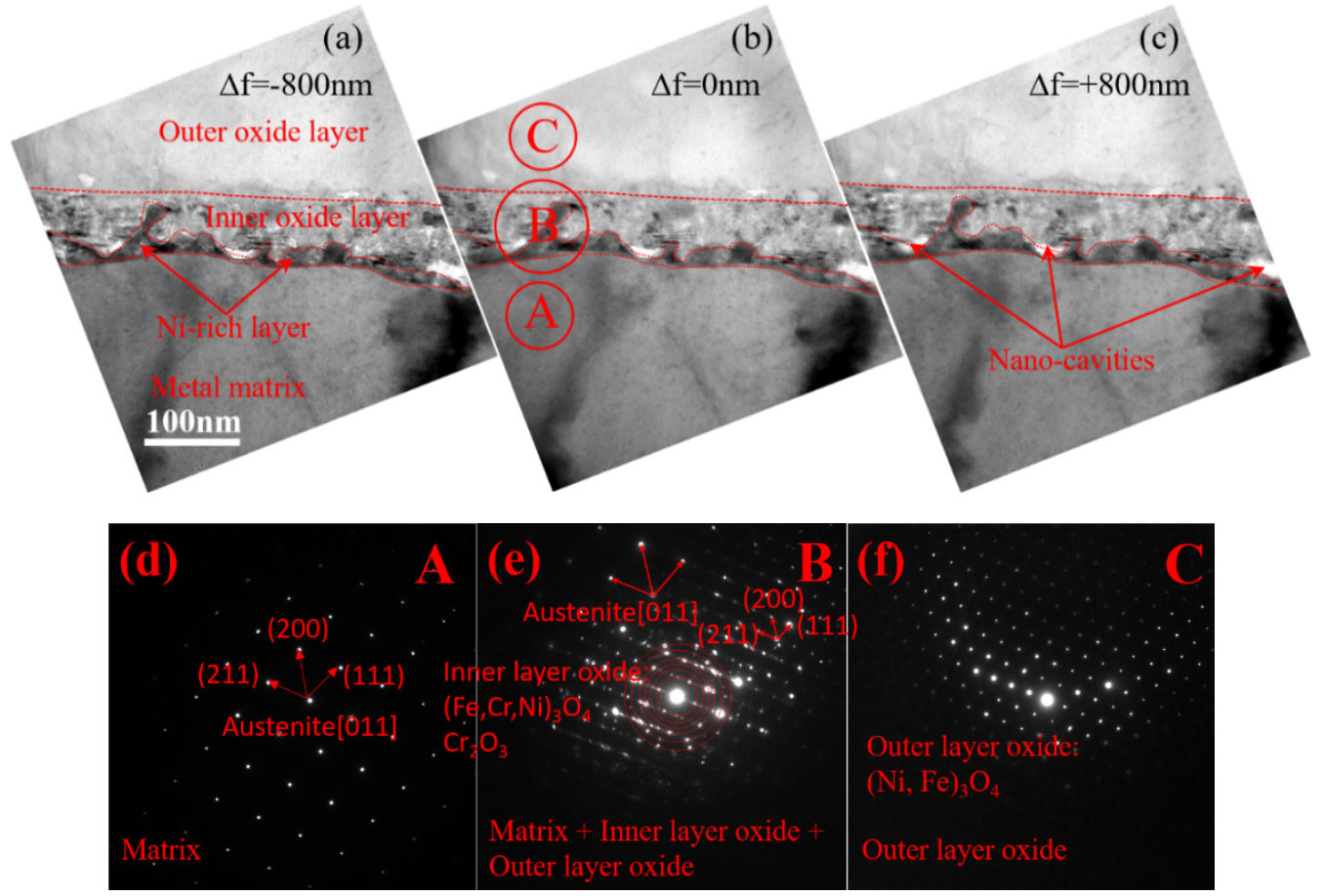

Fig. 5. Fresnel-contrast TEM images taken at (a) underfocused, (b) focused, and (c) overfocused conditions to reveal the porosity of the surface oxide formed on Alloy 600 with a mirror finished surface (defocus value $=$ $\pm 800 \mathrm{~nm}$ ); (d) SAED pattern obtained from the matrix; (e) SAED pattern obtained from the matrix and surface oxide; (f) SAED pattern obtained from outer oxide.

\subsubsection{Intergranular oxidation}

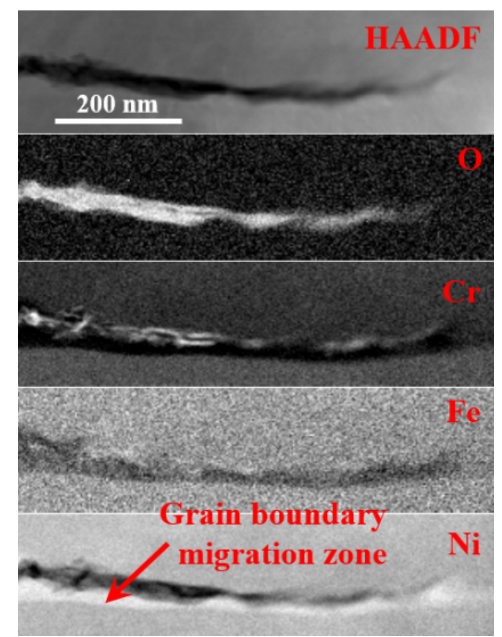

Fig. 6. The morphology and chemistry around the tip of a representative oxidized GB.

Five high-angle GBs after the corrosion test were prepared from the specimen with a mirror-finished surface by FIB. The intergranular oxidation depths vary from 1.8 to $2.5 \mu \mathrm{m}$. Both the morphology and chemistry around the tips of the oxidized GBs were analysed by TEM. Fig. 6 shows the HAADF image and EELS signal intensity maps around the tip of a representative oxidized GB. It is seen that the intergranular oxides are enriched in $\mathrm{Cr}$ and depleted in $\mathrm{Fe}$ and Ni. Further observation shows the existence of a Ni-rich and $\mathrm{Cr} / \mathrm{Fe}$-depleted zone aside 
the intergranular oxides. Since the signal intensity of Ni in the Ni-rich zone is greater than the unaffected matrix, it suggests that $\mathrm{Ni}$ expulsion has occurred in this region. The formation of this Ni-rich zone has been reported to be due to grain boundary migration $[13,19,20,24]$.

\subsection{Oxidation on the cold-worked surface}

TKD was conducted to examine the near surface region of the coupon with a cold-worked surface prior to the oxidation test. Four different regions were analysed by TKD, and one of the representative results is shown in Fig. 7. A deformation layer consisting of nano-grains is observed in the roughly-ground coupon, as shown in Figs. $7 \mathrm{a}$ and $\mathrm{b}$. The thickness of the deformation layer is $\sim 200 \mathrm{~nm}$. The KMO map in Fig. 7c shows that there is a high density of dislocations in the deformation layer, especially near the GBs of these nano-grains and the deformation bands. The deformation layer is not observed in the coupon with a mirror-finished surface (not shown). Fig. 8a shows the surface morphology of Alloy 600 with a cold-worked surface after exposure to the PWR primary water for $2000 \mathrm{~h}$. The surface oxide film appears to be compact and nearly no outer surface oxide particles are observed (see Fig. 8b).

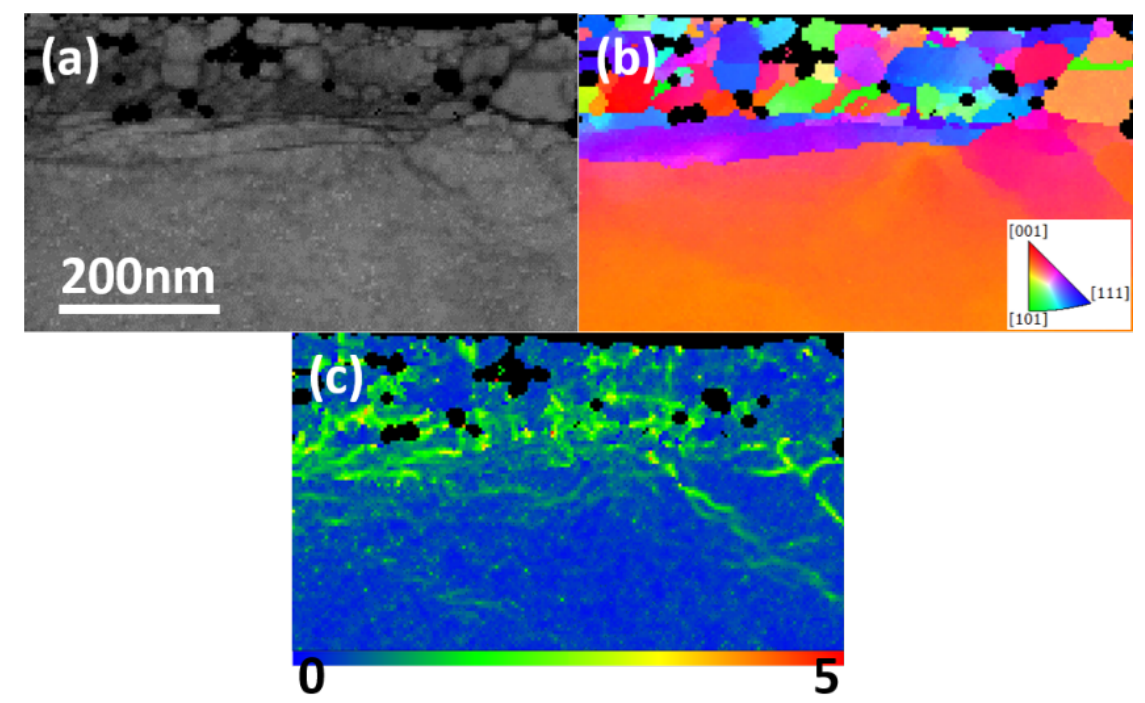

Fig. 7. TKD analysis acquired at the region close to the cold-worked surface (step size $=10 \mathrm{~nm}$ ) prior to the oxidation test: (a) image quality map; (b) IPFZ map; (c) KMO map.
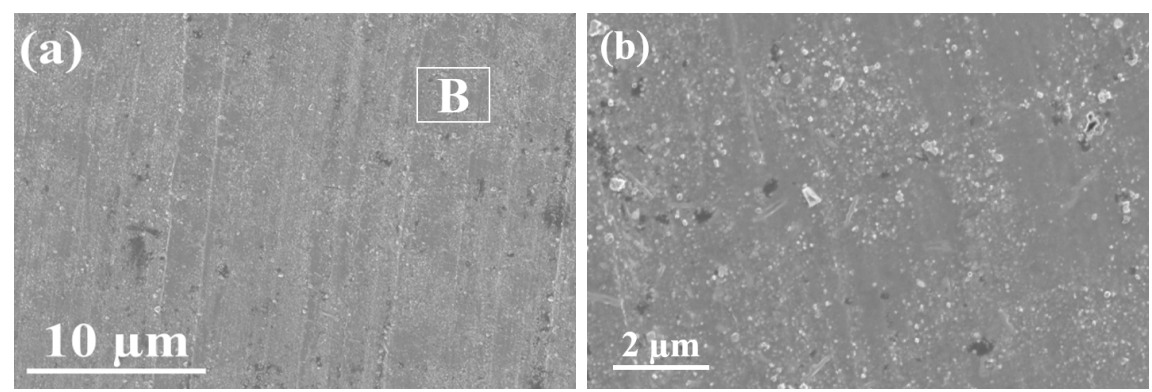

Fig. 8. (a) The surface morphologies of Alloy 600 with a cold-worked surface after exposure to the PWR primary water for 2000h; (b) magnified view of the rectangle area B in (a).

The HAADF image in Fig. 9a shows that oxidation has propagated into a deeper region ( $200 \mathrm{~nm})$ in the coupon with a cold-worked surface than that in the coupon with a mirror-finished surface $(\sim 100 \mathrm{~nm}$, excluding the OOL). Further observation reveals that the surface oxidation terminates at the deformation layer-matrix interface after $2000 \mathrm{~h}$ of exposure. However, the oxidation under the cold-worked surface is not uniform but oriented along the boundaries of the nano-grains and the deformation bands. The oxides in the deformation layer are enriched in $\mathrm{Cr}$ and depleted in $\mathrm{Fe}$ and $\mathrm{Ni}$. Although the nano-grains are not oxidized, the chemical composition in some of these nano-grains is different from that in the unaffected matrix. As shown in the region marked by the red dashed circle, $\mathrm{Ni}$ is enriched and the $\mathrm{Fe}$ and $\mathrm{Cr}$ are depleted (see Fig. 9b). Further observation reveals a Cr-rich thin top surface oxide film $(\sim 30 \mathrm{~nm})$. The EELS chemical composition analysis shows that the 
content of $\mathrm{Cr}$ in the thin oxide layer is $\sim 36$ at.\%, which is much higher than in the inner oxide layer of the coupon with a mirror-finished surface ( 20 at.\%).
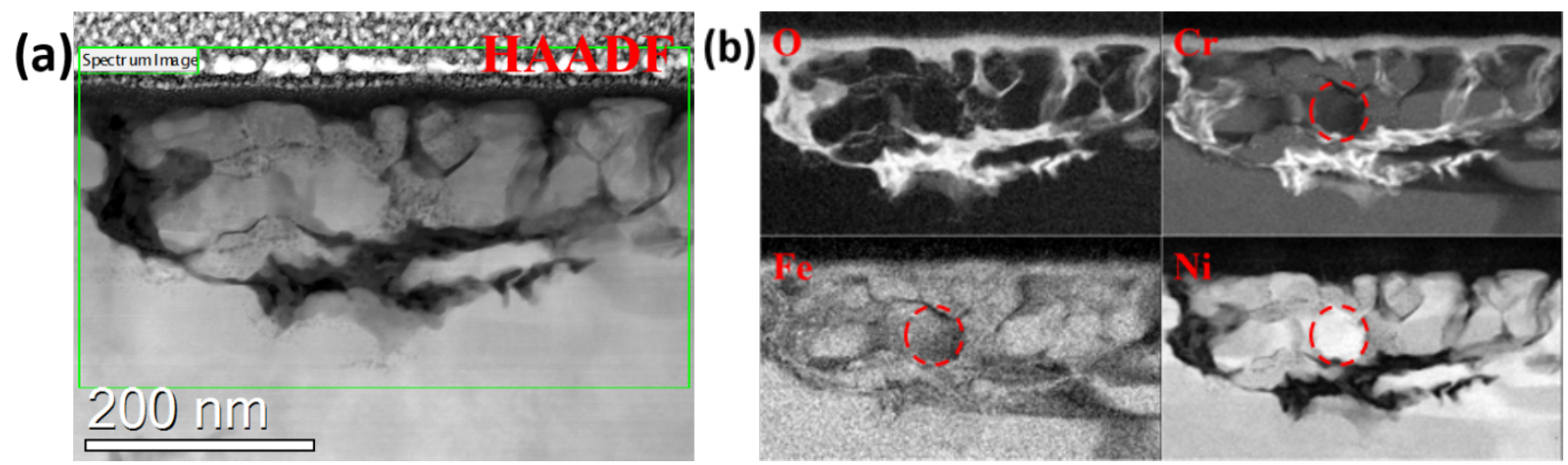

Fig. 9. (a) HAADF image and (b) EELS elemental O K edge and $\mathrm{Cr} / \mathrm{Fe} / \mathrm{Ni} \mathrm{L}$ edge maps (signal intensity) of Alloy 600 with a cold-worked surface after exposure for $2000 \mathrm{~h}$.

\subsection{Oxidation around IGSCC crack tip}

Four potentially active crack tips were prepared and analysed. Fig. 10a shows the HAADF image of one of the representative crack tips. Intergranular oxidation is observed to propagate ahead of the crack tip, forming a $\mathrm{Cr}$ rich intergranular oxidation zone (IOZ). The length of the IOZ is $\sim 60 \mathrm{~nm}$. EELS signal intensity maps around the crack tip are shown in Fig. 10a. A Ni-rich and $\mathrm{Cr} / \mathrm{Fe}$-depleted zone is observed around the crack tip. Further observation reveals that the signal intensity of $\mathrm{Ni}$ in the Ni-rich zone is greater than the unaffected matrix, indicating that $\mathrm{Ni}$ expulsion has occurred in this region. EELS line-scan is conducted to quantitatively show the chemical composition around the crack tip. The locations of the line-scans are marked in the HAADF image. $\mathrm{Cr}$ is revealed to be depleted in the unaffected GB (see Fig. 10b), which is caused by the thermal treatmentinduced GB sensitization [14, 41-43]. Cr appears to be severely depleted in the GB just ahead of the crack tip and $\mathrm{Ni}$ was significantly enriched (see Fig. 10c). Fig. 10d reveals that the intergranular oxidation propagates along the Ni-rich zone-matrix interface but not through the Ni-rich zone. Similar results have also been reported in the literature and the Ni-rich zone observed ahead of the tip has been proved to be GB migration (GBM) [13, $14,19,20,23,42,44,45]$.

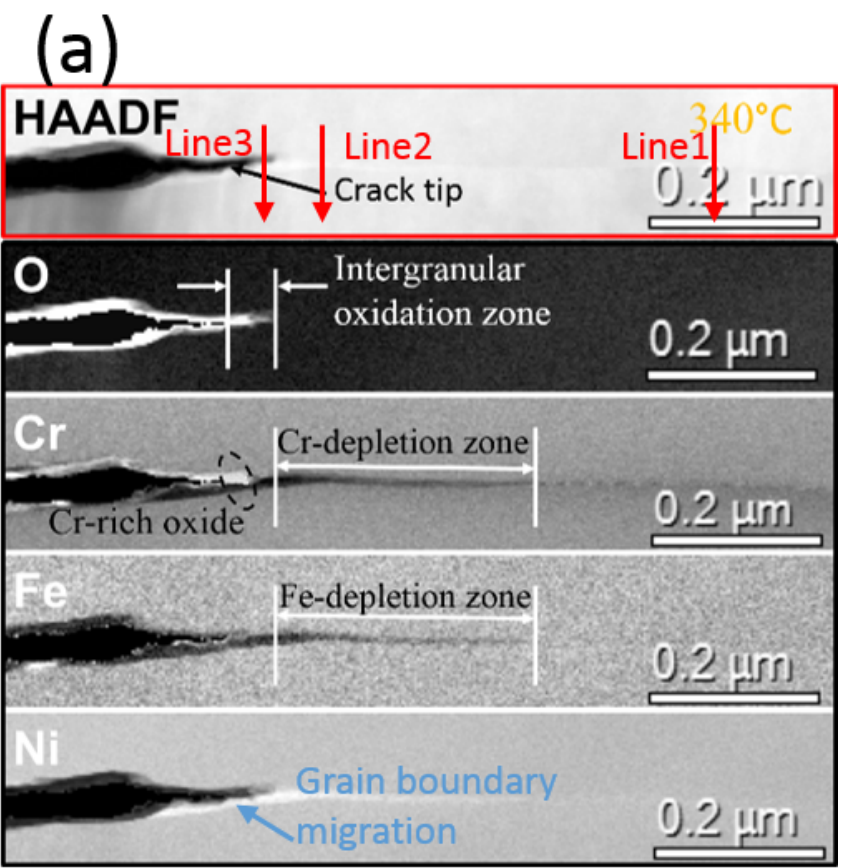


(b)

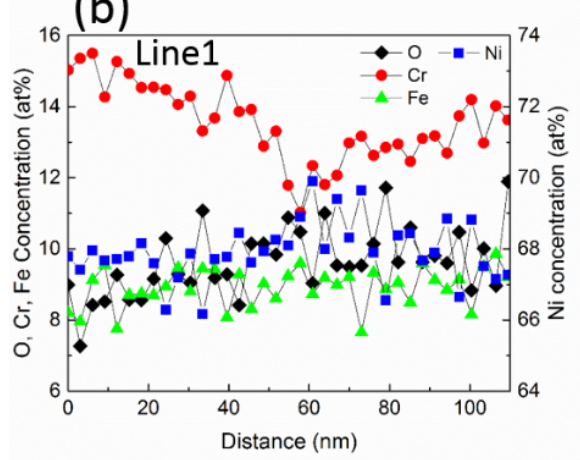

(c)

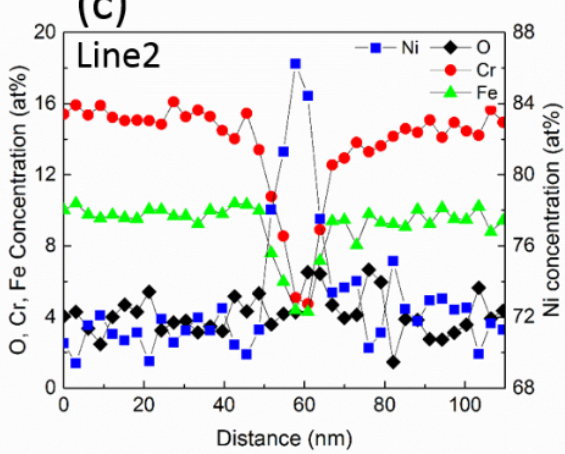

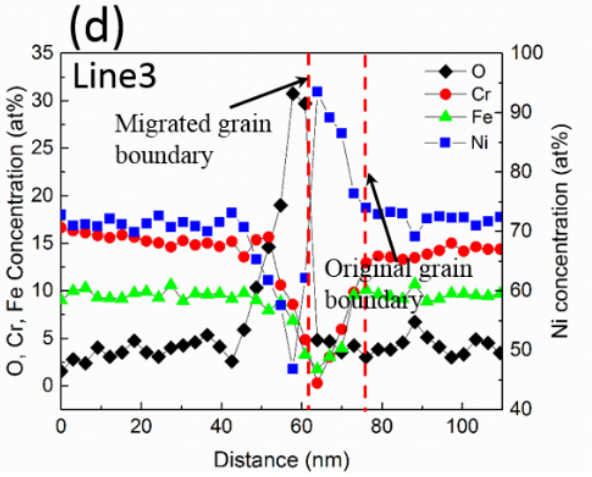

Fig. 10. (a) HAADF image of a crack tip sample prepared from Alloy 600 with indication of EELS line-scan locations and EELS elemental $\mathrm{O}-\mathrm{K}$ edge and $\mathrm{Cr} / \mathrm{Fe} / \mathrm{Ni} \mathrm{L}$ edge maps (signal intensity). Composition line profiles obtained through EELS analysis performed (b) at the original GB; (c) at the Cr-Fe depleted zone c); (d) at the IOZ.

\section{Discussion}

\subsection{Surface oxidation mechanism}

The surface oxide formed on Alloy 600 with a mirror-finished surface, after being exposed to simulated PWR primary water at $340^{\circ} \mathrm{C}$ for $2000 \mathrm{~h}$, has been studied in detail. The thickness of the surface oxide film is uniform and can be divided into two layers according to the different chemical composition in different layers: OOL and IOL. In addition, a thin Ni-rich layer is identified at the IOL-matrix interface due to the application of highresolution characterization.

\subsubsection{Outer oxide layer}

The OOL consists of numerous oxide particles with a Ni-Fe spinel structure, ranging from $500 \mathrm{~nm}$ to $5 \mu \mathrm{m}$. Since the distribution of these particles is discrete but not continuous, the OOL is believed to leave the specimen unprotected [24-32]. It is worth noting that the growth of the outer surface particles appears to be along a specific direction within one grain. The growth directions of the particles on different matrix grains appear to vary from grain to grain (see Fig. 3a), indicating that the growth direction of the OOL can be affected by the orientation of the matrix. SAED pattern reveals that the outer surface particles are epitaxial to the matrix. This phenomenon further proves that the growth of the OOL can be affected by the underneath matrix. Since Ni was observed in the OOL and depleted in the IOL, it is sensible to postulate that part of the $\mathrm{Ni}$ in the OOL is originated from the IOL. It is generally believed that the formation of the OOL is due to the precipitation of the oxidation products (originating from pipelines and specimen oxidation) on the specimen outer surface [24-32]. The observation of preferred precipitation orientation on different matrix grains in the present study suggests that the precipitation process can be affected by the underneath matrix grain. Since a large amount of $\mathrm{Ni}^{2+}$ is released from the coupon to the environment and involved in the precipitation of outer layer oxide particles, it is supposed that the oriented growth of the outer surface particles might be partially contributed by the outward diffusion of $\mathrm{Ni}^{2+}$. The detailed mechanism remains unclear and requires further investigation. 


\subsubsection{Inner oxide layer}

The thickness of the IOL in Alloy 600 is uniform and the structure appears to be compact, although nanocavities are observed at the interface between IOL and Ni-rich layer. Since the IOL-OOL interface is straight, it suggests that this interface used to be the original specimen surface. The phases of the IOL are mainly Cr-rich spinel. Although $\mathrm{Cr}_{2} \mathrm{O}_{3}$ has also been identified through SAED, $\mathrm{Cr}_{2} \mathrm{O}_{3}$ cannot be the dominant phase in the IOL due to the existence of $\mathrm{Fe}$ in Alloy 600. Compared with $\mathrm{Cr}_{2} \mathrm{O}_{3}$, the kinetics is more favourable for the formation of Fe-Cr spinel when Fe is added [19]. The SAED pattern shows that the IOL is composed of nanocrystallines and these nanocrystallines were epitaxial with the matrix, which is consistent with the literature [24, 30]. This indicates that the formation of the IOL is controlled by a solid-state diffusion process (solid-state growth).

The IOL is reported to play a critical role in protecting the material from further oxidation and the protectiveness of the IOL is affected by its chemical composition $[24,26]$. According to the results obtained from the EELS signal intensity line-scan (see the supplementary Fig. S1), the IOL is enriched in $\mathrm{Cr}$ and Fe, which are $\sim 57 \%$ and $\sim 69 \%$ higher than in the unaffected matrix, while Ni has been measured to be $\sim 91 \%$ lower than in the unaffected matrix. The increase in $\mathrm{Cr}$ and $\mathrm{Fe}$ might come from the Ni-rich layer since $\mathrm{Cr}$ and $\mathrm{Fe}$ are nearly exhausted in this layer. To confirm this hypothesis, the normalized signal density in the IOL and the Ni-rich layer can be compared to the unaffected matrix. The results show that the normalized signal density of $\mathrm{Cr}$ in these two layers of oxide is very similar to that in the unaffected matrix, proving that the enriched $\mathrm{Cr}$ in the IOL mainly came from the Ni-rich layer. However, the normalized signal density of $\mathrm{Fe}$ in the two layers of oxide is still $\sim 47 \%$ higher than in the unaffected matrix, indicating that the $\mathrm{Fe}^{2+} / \mathrm{Fe}^{3+}$ in the solution could have diffused into the IOL. This phenomenon is also observed by Bruemmer et al. [46] in a study of the surface oxidation of a Ni-Cr binary alloy, in which the authors found extra Fe in the IOL. In contrast, the normalized signal density of $\mathrm{Ni}$ in the two layers of oxide is $\sim 77 \%$ lower than in the unaffected matrix, suggesting that the surface oxidation in Alloy 600 could lead to a severe dissolution of $\mathrm{Ni}^{2+}$. The dissolved $\mathrm{Ni}^{2+}$ could contribute to the formation of the OOL, as discussed in section 4.1.1. Once the outward diffusion of $\mathrm{Ni}^{2+}$ from the matrix into the oxide/water interface was affected by the matrix orientation, it is not surprising to see an orientation relationship between the OOL and the matrix.

\subsubsection{Ni-rich layer}

Due to the high-resolution of the EELS analysis, a thin Ni-rich layer $(\sim 30 \mathrm{~nm})$ with different chemical composition compared to the unaffected matrix is observed. Although the surface oxidation of Ni-based alloys in PWR primary water has been intensively studied in the literature [24-32], the formation of the Ni-rich layer in the matrix beneath the IOL is still unclear. Sennour et al. [24] and Marchetti et al. [26] did not observe a Nirich layer while Panter et al. [47] and Delabrouille [48] observed a Cr-depleted and Ni-rich layer. The authors $[47,48]$ attributed the formation of this $\mathrm{Ni}$-rich layer to the outward diffusion of $\mathrm{Cr}$ and $\mathrm{Fe}$, resulting in the increase of the relative concentration of Ni. However, in the current study, we observed that the normalized signal density of $\mathrm{Ni}$ in the Ni-rich layer is higher than in the unaffected matrix (see supplementary Fig. S1b and Fig. 4b). This indicates that the formation of the Ni-rich layer is not just because $\mathrm{Cr}$ and $\mathrm{Fe}$ have diffused out. In the meanwhile, a part of $\mathrm{Ni}$ in the IOL has been expulsed into this layer. Although the $\mathrm{Ni}$ expulsion has been rarely observed at temperatures under $360^{\circ} \mathrm{C}$, it has been frequently reported in the hydrogenated steam at temperatures above $400^{\circ} \mathrm{C}[15,23,49]$. Since the $\mathrm{Ni}$ expulsion is the result of lattice diffusion of $\mathrm{Ni}$, the low lattice diffusion of $\mathrm{Ni}$ at $360^{\circ} \mathrm{C}$ might be the reason why $\mathrm{Ni}$ expulsion rarely occurred at these temperatures. More details about the enhanced lattice diffusion of $\mathrm{Ni}$ at the relatively low temperature will be discussed below.

\subsection{The effects of dislocations on oxidation}

The TKD analysis confirms the existence of a deformation layer under the cold-worked surface, with a thickness of $\sim 200 \mathrm{~nm}$. This layer is caused by the rough mechanical grinding since it is not observed on the mirror-finished surface. Compared with the unaffected matrix, the density of dislocations is much higher in the deformation layer, especially at the GBs of the nano-grains and deformation bands. The formation of the deformation layer is widely believed to enhance the outward diffusion of $\mathrm{Cr}$, resulting in the formation of a more compact surface 
oxide film [37-39, 50,51]. The enhanced outward diffusion of $\mathrm{Cr}$ has also been confirmed in this study, since the content of $\mathrm{Cr}$ in the surface oxide film formed on the cold-worked surface is much higher than that in the mirror-finished surface ( $\sim 36$ vs. $\sim 20$ at.\%). Considering the relatively high content of $\mathrm{Cr}$, it is likely that the thin oxide film formed on the cold-worked surface mainly consists of $\mathrm{Cr}_{2} \mathrm{O}_{3}$. The thickness of the oxide film formed on the cold-worked surface is much thinner than that on the mirror-finished surface $(\sim 30 \mathrm{vs.} \sim 100 \mathrm{~nm})$ after $2000 \mathrm{~h}$ of exposure, suggesting that the oxide film containing more $\mathrm{Cr}$ is more protective than that containing lower $\mathrm{Cr}$. In addition, since there is nearly no oxide particles on the cold-worked surface after the oxidation test, it further proves that thin oxide film formed on the cold-worked surface is more protective and could inhibit the cation low to the specimen surface. However, the nano-GBs in the deformation layer have been preferentially oxidized. The depth of the intergranular oxidation on the cold-worked surface is $\sim 200 \mathrm{~nm}$, which is around two times higher than that on the mirror-finished surface $(\sim 100 \mathrm{~nm})$. This observation suggests that although the compact thin top surface oxide film can protect the grain body effectively, the inward diffusion of oxygen along the nano-GBs has not been effectively prevented. The enhanced oxidation along the nano-GBs is supposed to be due to the accumulation of dislocations at these regions since the dislocations can accelerate the fast diffusion of metallic and nonmetallic species and result in fast oxidation [27, 35-40, 52-58]. Further observation shows that although the nano-GBs are preferentially oxidized, the oxidation is mainly limited in the deformation layer, and the underneath matrix has been well protected. As a result, we believe that the thin deformation layer is still beneficial to protect the base metal from further oxidation.

Although the oxidation in the deformation layer is mainly intergranular, the chemical composition in some of these nano-grains has been altered: being enriched in $\mathrm{Ni}$ and depleted in $\mathrm{Fe}$ and $\mathrm{Cr}$ (see Fig. 9b). In addition, since the signal intensity of $\mathrm{Ni}$ in these regions is higher than in the unaffected matrix, it suggests that $\mathrm{Ni}$ expulsion has occurred, which is similar to the Ni-rich layer on the mirror-finished surface. Compared with the Ni-rich layer in the mirror-finished surface, the size of the Ni-rich zone in the cold-worked surface is much higher. This phenomenon appears to be important in the understanding of IGSCC since a Ni-rich region has always been observed ahead of IGSCC crack tips and is suspected to play an important role in IGSCC [13, 14, $18-20,23,42,44,45]$. As a result, it is necessary to obtain a mechanistic understanding of the formation of Nirich zone within the deformation layer.

The depletion of $\mathrm{Cr}$ and $\mathrm{Fe}$ inside the nano-grians might be due to the preferential oxidation of $\mathrm{Cr}$ and $\mathrm{Fe}$ at the GBs of the nano-grains driving the outward diffusion of $\mathrm{Cr}$ and $\mathrm{Fe}$ from the grain interior. Due to the relatively high hydrogen content in the water and the low oxygen affinity for $\mathrm{Ni}$, it is more difficult for $\mathrm{Ni}$ to be oxidized than $\mathrm{Fe}$ and $\mathrm{Cr}$, resulting in the increase of relative content of $\mathrm{Ni}$ in these grains. According to Fig. 9b, the signal intensity of $\mathrm{Ni}$ in these grains is higher than in the unaffected matrix, suggesting that the outside $\mathrm{Ni}$ has diffused into these grains through lattice diffusion. The increase in $\mathrm{Ni}$ within these regions might originate from the region now occupied by the intergranular oxides, where is depleted in Ni. Although Ni expulsion in the hydrogenated environment has been reported by many researchers [15, 23, 49, 59], they observed it at temperatures above $400^{\circ} \mathrm{C}$. However, it is generally considered that the lattice diffusion of $\mathrm{Ni}$ at the normal operating temperature of PWR is negligible. As a result, there must be some other factors contributing to the enhanced lattice diffusion of $\mathrm{Ni}$ in these regions. According to the work conducted by Arioka et al. [60, 61], cold work can significantly increase the vacancies in the material, which can remarkably enhance the lattice diffusion of Ni. The material used in this study is $20 \%$ cold-worked and the surface mechanical polishing could further increase the density of vacancies in the deformation layer, which would accelerate the lattice diffusion of Ni. As a result, it is sensible to postulate that the Ni expulsion occurred in the deformation layer was the result of enhanced lattice diffusion of $\mathrm{Ni}$ from the region now occupied by the intergranular oxides into these highly deformed grain bodies. The larger size of the Ni-rich zone in the deformation layer than that in the mirrorfinished surface can also be explained by the higher vacancy density in the deformation layer than in the coupon with a mirror-finished surface.

\subsection{Comparison between surface and crack tip oxidation}


The crack tips studied in this work are prepared from the deepest region of the IGSCC cracks (see Fig. 2), suggesting that the cracks are potentially active at the end of the autoclave testing. Although the length of the oxide ahead of the crack tip can be measured, its oxidation rate still cannot be calculated since the exact crack tip oxidation time is unknown. According to the IOZ observed ahead of the crack tip and the work conducted in the literature, the mechanism controlling the IGSCC of Alloy 600 is supposed to be the intergranular selective oxidation [2, 8-15, 19, 20, 23, 62-64]. Since the IOZ can always be observed ahead of IGSCC crack tips, the intergranular selective oxidation mechanism believes that the intergranular oxidation rate in the region ahead of the crack tips should be faster than or equivalent to the IGSCC CGR $[2,14,39]$. As a result, the minimum oxidation rate in the region ahead of IGSCC crack tips in this study can be estimated by the measured IGSCC CGR $\left(1.6 \times 10^{-6} \mathrm{~mm} / \mathrm{s}\right)$.

The oxidation rate of the GBs under the mirror-finished surface can be calculated based on the measured depth of the oxidized GBs $(1.8-2.5 \mu \mathrm{m})$. The maximum intergranular oxidation depth $(2.5 \mu \mathrm{m})$ is used to calculate the intergranular oxidation rate and the calculated oxidation rate is $3.5 \times 10^{-10} \mathrm{~mm} / \mathrm{s}$, which is four orders of magnitude slower than the crack tip oxidation rate. The enhanced oxidation rate in the region ahead of the IGSCC crack tips could be due to the applied-stress around the IGSCC crack tips during the SCC testing since the applied-stress is believed to remarkably accelerate the diffusion of metallic and nonmetallic species, resulting in faster oxidation [55].

IOZ has been observed by many researchers and is reported to be associated with the formation of a Ni-rich region $[13,14,19,20,23,42,44,45,65]$. The Ni-rich region is also observed in front of the crack tips examined in this work, which is believed to be associated with the GBM [13,14, 19, 20, 23, 42, 44, 45, 65]. Since the Nirich region is depleted in $\mathrm{Cr}$ and $\mathrm{Fe}$, the formation of GBM is believed to be due to outward diffusion of $\mathrm{Cr}$ and Fe, which is referred to as diffusion induced GBM (DIGM) in the literature [13, 19, 20, 23, 42, 44, 45, 65]. Since the signal intensity of $\mathrm{Ni}$ in the Ni-rich region is higher than in the unaffected matrix, it suggests that the $\mathrm{Ni}$ from the surrounding region, possibly the region now occupied by the IOZ, has been expulsed into this region. As a result, based on the results discussed above, it is sensible to postulate that the formation of DIGM ahead of the IGSCC crack tip to be due to the outward diffusion of $\mathrm{Cr}$ and $\mathrm{Fe}$ as well as the $\mathrm{Ni}$ expulsion. Although the role of solute elemental diffusion ( $\mathrm{Cr}$ and $\mathrm{Fe}$ ) on the DIGM has been identified by many researchers $[13,19,20,23,42,44,45,66]$, the role Ni expulsion has not attracted enough attention [56, 67]. In addition, the DIGM has been widely observed around the IGSCC crack tips and oxidized grain boundaries [20, $44,45,68]$, while the effects of the DIGM on the IGSCC still remain unclear, which require further investigation.

It is worth noting that the chemical composition around the tip of the intergranular oxide is very similar to that observed around the SCC crack tips. Both selective oxidation of $\mathrm{Cr}$ and DIGM are observed, which suggests that the oxidation mechanism controlling the oxidation of the stagnant grain boundaries is similar to that of the SCC crack tips. The applied stress at the SCC crack tips may only accelerate the process of oxidation but not change the mechanism. To confirm this hypothesis, more research will be needed.

\section{Conclusions}

The microstructure and chemistry of the intragranular and intergranular oxides formed on a mirror-finished surface of Alloy 600 were characterized in detail through high-resolution characterization after exposure to the simulated PWR primary water. The surface oxide film formed on the mirror-finished surfaces has a duplex structure: OOL and IOL. The OOL consists of a large number of oxide particles. The growth of these particles follows a specific direction and the growth direction varies from matrix grain to grain. The crystallographic orientation of the oxide particle is epitaxial with the underneath matrix grain, suggesting that the formation of the particles is affected by the crystallographic orientation of the matrix grain. The IOL is composed of nanocrystallites and epitaxial to the metal matrix underneath. A Ni-rich layer forms at the IOL-matrix interface through Ni expulsion, which is believed to be due to the prior $20 \%$ cold-work enhancing the lattice diffusion of Ni. 
A thin deformation layer is observed under the cold-worked surface and this layer consists of nano-sized grains. The oxide film formed on the cold-worked surface is very compact and the intragranular oxidation is effectively restrained, while a severe oxidation occurs along the boundaries of the nano-grains and deformation bands due to the preferential accumulation of dislocations. The size of the Ni-rich region in the deformation layer is larger than in the mirror-finished surface. The formation of the Ni-rich zone is also attributed to Ni expulsion. The greater extent of $\mathrm{Ni}$ expulsion under the cold-worked surface than that of the mirror-finished surface is believed to be due to a higher content of vacancies.

Oxidation does not terminate at the crack tip, but propagates into a deeper region along the GB, forming an IOZ. The oxidation rate in the region ahead of the crack tips is around four orders of magnitude faster than that of the stagnant GBs. The enhanced oxidation in the region ahead of the crack tips is supposed to be due to the appliedstress during the SCC testing. Ni expulsion also occurs around the tips of SCC crack and oxidized GB, resulting in the formation of DIGM.

\section{Data availability statement}

All the data discussed are directly presented in the paper and therefore they are immediately accessible.

\section{Acknowledgements}

The EPSRC (EP/K040375/1, EP/N010868/1, and EP/R009392/1) grants are acknowledged for funding this research. The authors would like to thank Institute of Nuclear Safety Systems (Japan) and Shanghai Jiao Tong University (China) for providing the samples used in this study. Profs. Sergio Lozano-Perez and Lefu Zhang are acknowledged for useful discussion.

\section{Reference}

[1] H. Coriou, L. Crall, Y. L. Gall, S. Vettier, 3rd Metallurgy Conf. on Corrosion, Saclay (Amsterdam, The Netherlands: North Holland Publishing Co., 1959), 1960, pp. 161-169.

[2] P.M. Scott, M. Le Calver. "Some possible mechanisms of intergranular stress corrosion cracking of alloy 600 in PWR primary water". In Proceedings of the sixth international symposium on environmental degradation of materials in nuclear power systems-water reactors, (TMS, 1993), 657-665.

[3] H.K. Birnbaum, P. Sofronis. Hydrogen-enhanced localized plasticity-a mechanism for hydrogen-related fracture, Materials Science and Engineering: A 176(1994) 191-202.

[4] F.P. Ford. Quantitative prediction of environmentally assisted cracking, Corrosion 52 (1996) 375-395.

[5] T. Magnin, A. Chambreuil, B. Bayle. The corrosion-enhanced plasticity model for stress corrosion cracking in ductile fcc alloys, Acta Materialia 44 (1996) 1457-1470.

[6] D. Du, J. Wang, K. Chen, L. Zhang. Stress corrosion cracking behavior of warm forged 316L stainless steel at different orientations, Journal of Nuclear Materials 522 (2019) 220-225.

[7] D. Du, K. Chen, L. Yu, H. Lu, L. Zhang, X. Shi, X. Xu. SCC crack growth rate of cold worked 316L stainless steel in PWR environment, Journal of Nuclear Materials 456 (2015) 228-234.

[8] B.M. Capell, G.S. Was. Selective internal oxidation as a mechanism for intergranular stress corrosion cracking of Ni-Cr-Fe alloys, Metallurgical and Materials Transactions A 38 (2007) 1244-1259.

[9] M. Meisnar, A. Vilalta-Clemente, M. Moody, K. Arioka, S. Lozano-Perez. A mechanistic study of the temperature dependence of the stress corrosion crack growth rate in SUS316 stainless steels exposed to PWR primary water, Acta Materialia114 (2016) 15-24.

[10] L.E. Thomas, S.M. Bruemmer. High-resolution characterization of intergranular attack and stress corrosion cracking of Alloy 600 in high-temperature primary water, Corrosion 56(2000) 572-587.

[11] S.M. Bruemmer, L.E. Thomas. High- resolution analytical electron microscopy characterization of corrosion and cracking at buried interfaces, Surface and Interface Analysis 31 (2001) 571-581.

[12] S. Lozano-Perez, J. M. Titchmarsh. TEM investigations of intergranular stress corrosion cracking in austenitic alloys in PWR environmental conditions, Materials at High Temperatures 20 (2003) 573-579.

[13] S.Y. Persaud, B. Langelier, A. Korinek, S. Ramamurthy, G. A. Botton, R.C. Newman. Characterization of initial intergranular oxidation processes in alloy 600 at a sub-nanometer scale, Corrosion Science 133 (2018) $36-47$. 
[14] Z. Shen, K. Arioka, S. Lozano-Perez. A mechanistic study of SCC in Alloy 600 through high-resolution characterization, Corrosion Science 132(2018) 244-259.

[15] B. Langelier, S. Y. Persaud, R. C. Newman, and G. A. Botton. An atom probe tomography study of internal oxidation processes in Alloy 600, Acta Materialia 109 (2016) 55-68.

[16] D. Du, K. Chen, H. Lu, L. Zhang, X. Shi, X. Xu, P.L. Andresen. Effects of chloride and oxygen on stress corrosion cracking of cold worked 316/316L austenitic stainless steel in high temperature water, Corrosion Science 110 (2016) 134-142.

[17] K. Chen, J. Wang, H. Su, L. Zhang. Investigation on the stress corrosion crack initiation and propagation behavior of alloy 600 in high-temperature water, Corrosion 74 (2018) 1395-1405.

[18] Z. Shen, M. Meisnar, K. Arioka, S. Lozano-Perez. Mechanistic understanding of the temperature dependence of crack growth rate in alloy 600 and 316 stainless steel through high-resolution characterization, Acta Materialia 165 (2019) 73-86.

[19] D.K. Schreiber, M.J. Olszta, S.M. Bruemmer. Grain boundary depletion and migration during selective oxidation of $\mathrm{Cr}$ in a $\mathrm{Ni}-5 \mathrm{Cr}$ binary alloy exposed to high-temperature hydrogenated water, Scripta Materialia 89 (2014) 41-44.

[20] L. Volpe, M. G. Burke, F. Scenini. Understanding the role of diffusion induced grain boundary migration on the preferential intergranular oxidation behaviour of Alloy 600 via advanced microstructural characterization, Acta Materialia 175 (2019) 238-249.

[21] J. Wang, H. Su, F. Ajmand, L. Zhang, K. Chen. Effects of corrosion potential, dissolved oxygen, and chloride on the stress corrosion cracking susceptibility of a 316NG stainless steel weld joint, Corrosion 75 (2019) 946-959.

[22] P.L. Andresen, J. Hickling, A. Ahluwalia, J. Wilson. Effects of hydrogen on stress corrosion crack growth rate of nickel alloys in high-temperature water, Corrosion 64 (2008) 707-720.

[23] G. Bertali, F. Scenini, M. G. Burke. Advanced microstructural characterization of the intergranular oxidation of Alloy 600, Corrosion Science 100 (2015) 474-483.

[24] M. Sennour, L. Marchetti, F. Martin, S. Perrin, R. Molins, M. Pijolat. A detailed TEM and SEM study of Ni-base alloys oxide scales formed in primary conditions of pressurized water reactor, Journal of Nuclear Materials 402 (2010) 147-156.

[25] J.H. Liu, R. Mendonça, R.W. Bosch, M.J. Konstantinović. Characterization of oxide films formed on alloy 182 in simulated PWR primary water, Journal of Nuclear Materials 393 (2009) 242-248.

[26] L. Marchetti, S. Perrin, F. Jambon, M. Pijolat. Corrosion of nickel-base alloys in primary medium of pressurized water reactors: New insights on the oxide growth mechanisms and kinetic modelling, Corrosion Science 102 (2016) 24-35.

[27] H. Lefaix-Jeuland, L. Marchetti, S. Perrin, M. Pijolat, M. Sennour, R. Molins. Oxidation kinetics and mechanisms of Ni-base alloys in pressurised water reactor primary conditions: Influence of subsurface defects, Corrosion Science 53 (2011) 3914-3922.

[28] W. Kuang, X. Wu, E.-H. Han. Influence of dissolved oxygen concentration on the oxide film formed on alloy 690 in high temperature water, Corrosion Science 69 (2013) 197-204.

[29] Z. Shen, J. Dohr, S. Lozano-Perez, The effects of intergranular carbides on the grain boundary oxidation and cracking in a cold-worked Alloy 600. Corrosion Science, 155(2019) 209-216.

[30] W. Kuang, M. Song, P. Wang, G.S. Was. The oxidation of alloy 690 in simulated pressurized water reactor primary water, Corrosion Science 126 (2017) 227-237.

[31] F. Huang, J. Wang, E.H. Han, W. Ke. Microstructural characteristics of the oxide films formed on Alloy 690 TT in pure and primary water at 325 C, Corrosion Science 76 (2013) 52-59.

[32] T. Terachi, N. Totsuka, T. Yamada, T. Nakagawa, H. Deguchi, M. Horiuchi, M. Oshitani. Influence of dissolved hydrogen on structure of oxide film on alloy 600 formed in primary water of pressurized water reactors, Journal of Nuclear Science and Technology 40 (2003) 509-516.

[33] P.M. Scott, M.C. Meunier, D. Deydier, S. Sylvestreand, A. Trenty. An analysis of Bafle/Former bolt cracking in French PWR, in: Environmentally assisted cracking: Predictive methods for risk assessment and evaluation of materials, ASTM 1401.

[34] Z. Shen, D. Du, L. Zhang, S. Lozano-Perez. An insight into PWR primary water SCC mechanisms by comparing surface and crack oxidation, Corrosion Science 148 (2019) 213-227. 
[35] Y. Han, J. Mei, Q. Peng, E.H. Han, W. Ke. Effect of electropolishing on corrosion of Alloy 600 in high temperature water, Corrosion Science 98 (2015) 72-80.

[36] Z. Zhang, J. Wang, E.H. Han, W. Ke. Influence of dissolved oxygen on oxide films of Alloy 690TT with different surface status in simulated primary water, Corrosion Science 53 (2011) 3623-3635.

[37] F. Scenini, R.C. Newman, R.A. Cottis, R.J. Jacko. Effect of surface preparation on intergranular stress corrosion cracking of alloy 600 in hydrogenated steam, Corrosion 64 (2008) 824-835.

[38] Z. Zhai, M.B. Toloczko, M.J. Olszta, S.M. Bruemmer. Stress corrosion crack initiation of alloy 600 in PWR primary water, Corrosion Science 2017 (123) 76-87.

[39] Z. Shen, K. Chen, D. Tweddle, G. He, K. Arioka, S. Lozano-Perez. Characterization of the crack initiation and propagation in Alloy 600 with a cold-worked surface, Corrosion Science 152 (2019) 82-92.

[40] R. Morris, N. Lewis, D.S. Morton. 3D analysis of surface treatment effects on the oxidation of grain boundaries in Alloy 600. In: Proceedings of the 16th International Symposium on Environmental Degradation of Materials in Nuclear Power Systems-Water Reactors, Ashville, NC, USA, TMS/NACE, 2013.

[41] K. Arioka, T. Yamada, T. Miyamoto, M. Aoki. Intergranular Stress Corrosion Cracking Growth Behavior of Ni-Cr-Fe Alloys in Pressurized Water Reactor Primary Water. Corrosion, 70(2014): 695-707.

[42] B. Langelier, S.Y. Persaud, A. Korinek, T. Casagrande, R.C. Newman, G.A. Botton. Effects of boundary migration and pinning particles on intergranular oxidation revealed by $2 \mathrm{D}$ and $3 \mathrm{D}$ analytical electron microscopy, Acta Materialia 131 (2017) 280-295.

[43] Z. Shen, J. Liu, K. Arioka, S. Lozano-Perez. On the role of intergranular carbides on improving the stress corrosion cracking resistance in a cold-worked alloy 600, Journal of Nuclear Materials 514 (2019) 50-55.

[44] W. Kuang, M. Song, G.S. Was. Insights into the stress corrosion cracking of solution annealed alloy 690 in simulated pressurized water reactor primary water under dynamic straining, Acta Materialia 151 (2018) 321333.

[45] Z. Shen, P. Karamched, K. Arioka, S. Lozano-Perez. Observation and quantification of the diffusioninduced grain boundary migration ahead of SCC crack tips, Corrosion Science 147 (2019) 163-168.

[46] S.M. Bruemmer, M.J. Olszta, M.B. Toloczko, D.K. Schreiber. Grain boundary selective oxidation and intergranular stress corrosion crack growth of high-purity nickel binary alloys in high-temperature hydrogenated water, Corrosion Science 131 (2018) 310-323.

[47] J. Panter, B. Viguier, J.M. Cloué, M. Foucault, P. Combrade, E. Andrieu. Influence of oxide films on primary water stress corrosion cracking initiation of alloy 600, Journal of Nuclear Materials 348 (2006) 213221.

[48] F. Delabrouille, B. Viguier, L. Legras, E. Andrieu. Effect of the chromium content on the corrosion of nickel based alloys in primary water of pressurised nuclear reactors, Materials at High Temperatures 22 (2005) 287-292.

[49] S.Y. Persaud, A. Korinek, J. Huang, G.A. Botton, R.C. Newman. Internal oxidation of Alloy 600 exposed to hydrogenated steam and the beneficial effects of thermal treatment, Corrosion Science 86 (2014) 108-122.

[50] L. Chang, L. Volpe, Y.L. Wang, M.G. Burke, A. Maurotto, D. Tice, S. Lozano-Perez, F. Scenini. Effect of machining on stress corrosion crack initiation in warm-forged type 304L stainless steel in high temperature water, Acta Materialia 165 (2019) 203-214.

[51] L. Chang, M.G. Burke, F. Scenini, Understanding the effect of surface finish on stress corrosion crack initiation in warm-forged stainless steel 304L in high-temperature water, Scripta Materialia 164 (2019) 1-5.

[52] S. Ghosh, M.K. Kumar, V. Kain. High temperature oxidation behavior of AISI 304L stainless steel-Effect of surface working operations, Applied Surface Science 264 (2013) 312-319.

[53] S. Wang, Y. Hu, K. Fang, W. Zhang, X. Wang. Effect of surface machining on the corrosion behaviour of 316 austenitic stainless steel in simulated PWR water, Corrosion Science 126 (2017) 104-120.

[54] G. Han, Z. Lu, X. Ru, J. Chen, Q. Xiao, Y. Tian. Improving the oxidation resistance of 316L stainless steel in simulated pressurized water reactor primary water by electropolishing treatment, Journal of Nuclear Materials 467 (2015) 194-204.

[55] S. Cissé, L. Laffont, B. Tanguy, M.C. Lafont, E. Andrieu. Effect of surface preparation on the corrosion of austenitic stainless steel 304L in high temperature steam and simulated PWR primary water, Corrosion Science 56 (2012) 209-216. 
[56] S. Lozano-Perez, T. Yamada, T. Terachi, M. Schröder, C.A. English, G.D.W. Smith, C.R.M. Grovenor, B.L. Eyre. Multi-scale characterization of stress corrosion cracking of cold-worked stainless steels and the influence of Cr content, Acta Materialia 57 (2009) 5361-5381.

[57] S. Lozano-Perez, K. Kruska, I. Iyengar, T. Terachi, T. Yamada. The role of cold work and applied stress on surface oxidation of 304 stainless steel, Corrosion Science 56 (2012) 78-85.

[58] V. Kain, K. Chandra, K.N. Adhe, P.K. De. Effect of cold work on low-temperature sensitization behaviour of austenitic stainless steels, Journal of nuclear materials 334 (2004) 115-132.

[59] G. Bertali, F. Scenini, M.G. Burke. The effect of residual stress on the preferential intergranular oxidation of Alloy 600, Corrosion Science 111 (2016) 494-507.

[60] K. Arioka, Y. Iijima, T. Miyamoto. Rapid nickel diffusion in cold-worked type 316 austenitic steel at 360$500^{\circ} \mathrm{C}$, International Journal of Materials Research 108 (2017) 791-797.

[61] K. Arioka, Y. Iijima, T. Miyamoto. Rapid nickel diffusion in cold-worked carbon steel at $320-450^{\circ} \mathrm{C}$, Philosophical Magazine 95 (2015) 3577-3589.

[62] P.M. Scott, P. Combrade. General corrosion and stress corrosion cracking of alloy 600 in light water reactor primary coolants, Journal of Nuclear Materials 524 (2019) 340-375.

[63] B. Stellwag. The mechanism of oxide film formation on austenitic stainless steels in high temperature water, Corrosion Science 40 (1998) 337-370.

[64] J. Robertson. The mechanism of high temperature aqueous corrosion of stainless steels, Corrosion Science 32 (1991) 443-465.

[65] T. Terachi, T. Yamada, T. Miyamoto, K. Arioka. SCC growth behaviors of austenitic stainless steels in simulated PWR primary water, Journal of Nuclear Materials 426 (2012) 59-70.

[66] M.G. Burke, G. Bertali, E. Prestat, F. Scenini, S.J. Haigh. The application of in situ analytical transmission electron microscopy to the study of preferential intergranular oxidation in Alloy 600, Ultramicroscopy 176 (2017) 46-51.

[67] K. Kruska, S. Lozano-Perez, D.W. Saxey, T. Terachi, T. Yamada, G.D. Smith, Nanoscale characterisation of grain boundary oxidation in cold-worked stainless steels. Corrosion science 63(2012) 225-233.

[68] L. Volpe, M. G. Burke, F. Scenini. Correlation between Grain Boundary Migration and Stress Corrosion Cracking of Alloy 600 in Hydrogenated Steam. Acta Materialia 186 (2020) 454-466.

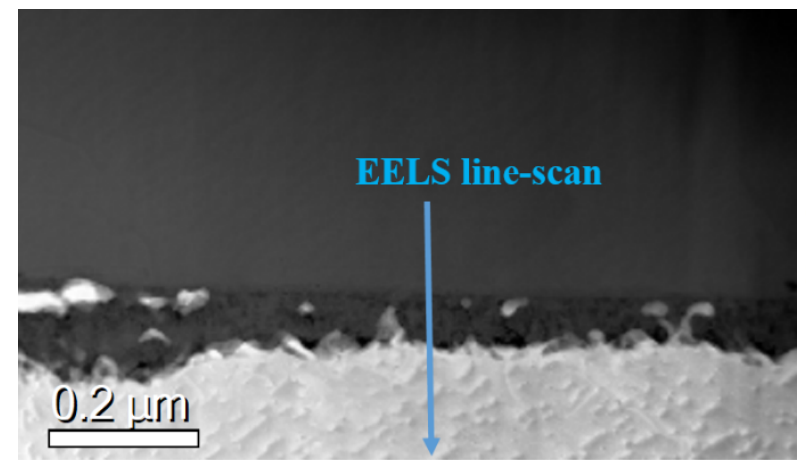

(a)

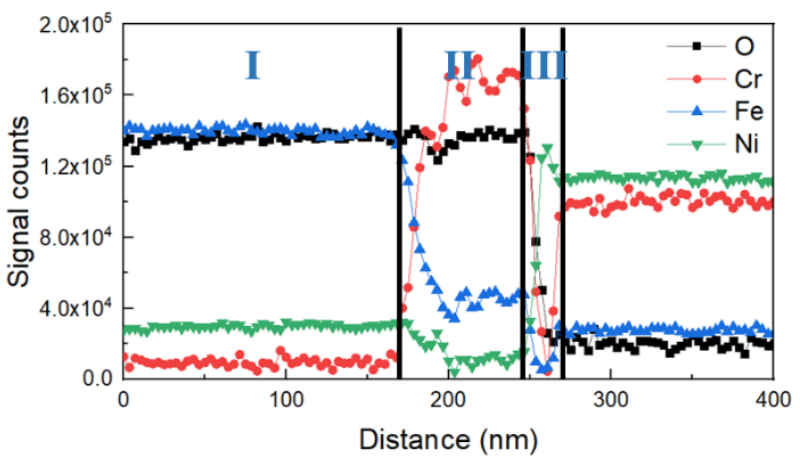

(b)

Fig. S1. The cross-section of the surface oxide formed on Alloy 600 with a mirror-finished surface. (a) HAADF image; (b) EELS elemental $\mathrm{O} \mathrm{K}$ edge and $\mathrm{Cr} / \mathrm{Fe} / \mathrm{Ni} \mathrm{L}$ edge line profiles (signal intensity). 